\title{
A TWO-DIMENSIONAL COUPLED ATMOSPHERE-ICE-SHEET-CONTINENT MODEL DESIGNED FOR PALEOCLIMATIC SIMULATIONS
}

\author{
by
}

\author{
M.B. Esch and K. Herterich
}

(Max-Planck-Institut für Meteorololgie, Bundesstrasse 55, 2000 Hamburg 13, Federal Republic of Germany)

\section{ABSTRACT}

We present a two-dimensional climate model to be used for basic dynamic studies on ice-age time scales $\left(10^{3}\right.$ to $10^{6}$ years). The model contains an ice sheet, where flow and temperature are calculated in a vertical plane, oriented in the north-south direction. The model ice sheet is forced by a zonally-averaged atmospheric energy-balance model, including a seasonal cycle and a simplified hydrological cycle, which specifies ice temperature and the mass balance at the ice-sheet surface. At the bottom of the ice sheet, the geothermal heat flux is prescribed. In addition, delayed bedrock sinking (or bedrock rising) is assumed.

A stationary state is achieved after 200000 model years. This long time scale is introduced by the slow evolution of the temperature field within the ice sheet. Using reasonable parameter values and presently observed precipitation patterns, modified by ice-sheet orography, the observed thickness to length ratio $(4 \mathrm{~km} / 3300 \mathrm{~km})$ of the Laurentide ice sheet can be simulated within a realistic build-up time (40000 years). Near the ice bottom, temperate regions developed. They may have had an important effect on ice-sheet build-up and ice-sheet decay.

\section{INTRODUCTION}

With the publication of the paper by Hays and others (1976), most of the scientists interested in ice-age modelling were convinced that the past changes in the global ice volume were related to variations of the Earth's orbital parameters. Encouraged by this result, a hierarchy of icesheet climate models was developed, intended to explain the link between radiation and ice volume. Only a few ice models were coupled to explicit atmospheric models, from which the snow budget driving the ice sheet could be derived. The most convincing results were obtained by Pollard (1983). He used an ice model following Birchfield and others (1981), and coupled it to an atmospheric model derived from a zonally-averaged and seasonal energy-balance equation (but with land-ocean contrast). Most of the icesheet climate models did not include a rigorous calculation of ice temperature, except the model of Morland-Hutter (Morland (1984), and following papers), which considers temperature-dependent planar flow in ice sheets but without application to specific ice-age conditions.

The aim of this work is not to make a further attempt to match data and model results, but rather to inspect the dynamics of the model without tuning the parameters to ice-age conditions. Especially, we are interested in the effect of ice temperature on the evolution of the ice-age ice sheets. Therefore, our ice-sheet model contains a fully coupled flow-temperature calculation and the parameterizations used in the atmospheric part of the model are fitted to modern conditions. In the next section we present a brief description of the coupled ice-atmosphere-continent model to simulate the build-up of the Laurentide ice sheet and to study stationary-state dynamics. In the final section we show model results, together with our conclusions.

\section{MODEL FORMULATION}

The ice-sheet model predicts the ice thickness $h$ along a meridian. The northern boundary of the model ice sheet lies at $70^{\circ} \mathrm{N}$ (the Arctic coast). The rate of change of ice-sheet thickness $h$ follows from the mass-balance equation:

$$
\frac{\partial h}{\partial t}=-\frac{\partial q}{\partial x}+b
$$

where $b$ is the annual snow balance and $q$ is the verticallyintegrated horizontal ice velocity $u$ (see Fig. 1). Delayed bedrock sinking (or rising) is described in the manner proposed by Weertman (1976), assuming a response time of 10000 years. For a more detailed review of the basic equations used for ice-sheet modelling see Paterson (1981) and Oerlemans and Van der Veen (1984).

The rate of change of ice temperature $T_{\mathrm{I}}$ within the ice sheet is controlled by the conservation of energy:

$$
\frac{\partial T_{\mathrm{I}}}{\partial t}+u \frac{\partial T_{\mathrm{I}}}{\partial x}+v \frac{\partial T_{\mathrm{I}}}{\partial z}=k \frac{\partial^{2} T_{\mathrm{I}}}{\partial z^{2}}+d
$$

where $u, v$ are the horizontal and vertical ice-velocity components, respectively, $k=36 \mathrm{~m} \mathrm{a}^{-1}$ the thermal diffusivity of ice, and $d$ the production of deformational heat (see below).

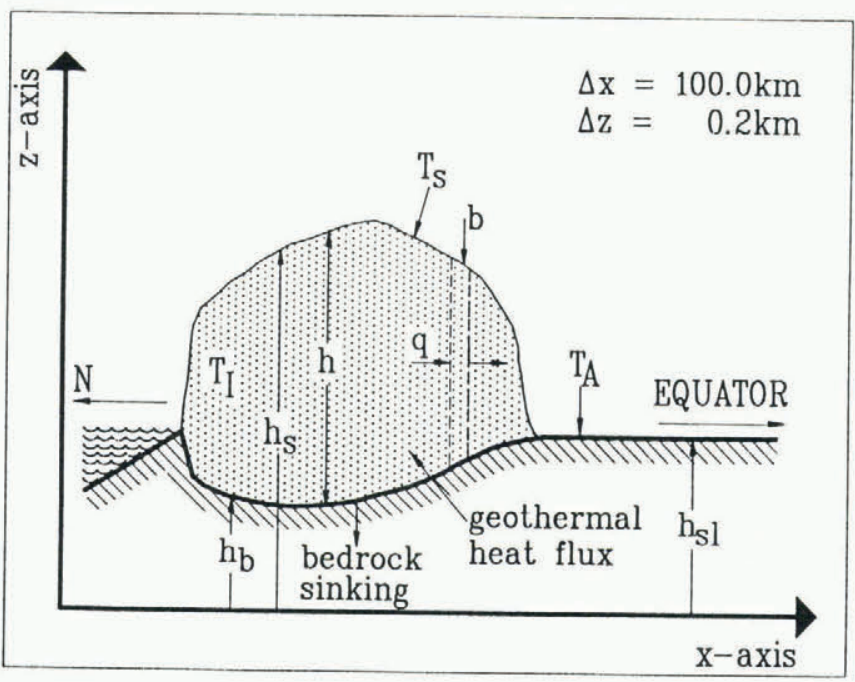

Fig. 1. Coordinate system of the coupled model and definition of model variables used in the text. The resolution of the ice-sheet model is $100 \mathrm{~km}$ in the horizontal direction and $200 \mathrm{~m}$ in the vertical direction. 
The surface temperature of the ice sheet is determined by the atmospheric model. At the ice-sheet bottom, a geothermal heat flux of $G=5.02 \times 10^{-2} \mathrm{~W} \mathrm{~m}^{-2}$ enters the ice. If the bottom temperature reaches the melting temperature $T_{\mathrm{M}}, T=T_{\mathrm{M}}$ replaces the flux boundary condition. The melting temperature is corrected for pressure: $T_{\mathrm{M}}=-a_{\mathrm{M}} h$, where $h$ is the ice thickness and $a_{M}=0.87 \mathrm{~K} \mathrm{~km}^{-1}$. The values of the physical constants used in the ice model were all taken from Paterson (1981).

The prognostic Equations (1) and (2) determine the time evolution of the ice sheet, provided the ice velocity is known. It can be derived from a set of diagnostic equations, the force balance and the empirical flow law for ice. In the shallow-ice approximation (Hutter, 1983), an analytical expression for the horizontal ice-velocity component $u$ can be derived (Herterich, 1988):

$$
u=u_{\mathrm{b}}-2(\rho g)^{n}\left|\frac{\partial h_{\mathrm{s}}}{\partial x}\right|^{n-1} \frac{\partial h_{\mathrm{s}}}{\partial x} \int_{h_{\mathrm{b}}}^{z} A\left(T^{\prime}\right)\left(h_{\mathrm{s}}-z^{\prime}\right)^{n} \mathrm{~d} z^{\prime}
$$

where $u_{\mathrm{b}}$ is the sliding velocity at the ice-sheet bottom $h_{\mathrm{b}}$ (being zero in the present model version) and $h_{\mathrm{s}}$ is the height of the ice surface. In the model, the density of ice $\left(\rho=910 \mathrm{~kg} \mathrm{~m}^{-3}\right)$ is constant, $g=9.8 \mathrm{~m} \mathrm{~s}^{-2}$ is the acceleration by Earth's gravity, and $n=3$. The temperaturedependent coefficient $A\left(T^{\prime}\right)$, where $T^{\prime}$ is the ice temperature measured above pressure-melting point, is based on measurements compiled by Paterson (1981).

The vertical velocity component $v$ follows from the incompressibility condition. Finally, the production of deformational heat $d$, defined by $d=\Sigma_{i, k} \dot{\varepsilon}_{i k} \sigma_{i k}$, where $\dot{\varepsilon}_{i k}$ and $\sigma_{i k}$ are the components of the strain-rate tensor and stress tensor, respectively, can be expressed in terms of the shape of the ice sheet:

$$
d=\frac{2}{\rho c} A\left(T^{\prime}\right)(\rho g)^{n+1}\left(h_{\mathrm{S}}-z\right)^{n+1}\left|\frac{\partial h_{\mathrm{s}}}{\partial x}\right|^{n+1}
$$

with $c=2 \times 10^{3} \mathrm{~m}^{2} \mathrm{~s}^{-2} K^{-1}$, the heat capacity of ice.

The above equations were formulated on a finitedifference grid. To prevent numerical instabilities, an up-wind scheme was used. The movement of the ice-sheet margin, where the shallow-ice approximation breaks down, was determined by mass conservation (Equation (1)).

The atmospheric model, forcing the model ice sheet, is based on a zonally-averaged energy-balance equation (cf. North, 1975), including a seasonal cycle, which is solved analytically for the atmospheric sea-level temperature $T_{\mathbf{A}}$ as a function of latitude. At the ice-sheet surface, the temperature is reduced with respect to sea-level temperature (cf. Bowman, 1982), using a lapse rate of $\gamma=-6 \mathrm{deg} / \mathrm{km}$. The mean annual surface temperature $T_{\mathrm{S}}$ of the ice sheet is obtained by integrating over the year.

The model precipitation as a function of latitude $\varphi$ in mid-latitudes is approximated by a Gaussian distribution:

$$
P=P_{0} \mathrm{e}^{-\left(\frac{\varphi-\varphi_{0}}{c}\right)^{2}} .
$$

where $P_{0}$ is a proportionality factor, determining the precipitation maximum at latitude $\varphi_{0}$, and $c$ a constant to give the best fit between model and present data. The position $\varphi_{0}$ is related to a critical temperature gradient, derived from the theory of baroclinic instability (Holton, 1979). In the model, $\varphi_{0}$ is shifted by $10^{\circ}$ in latitude during the year, in accordance with observations.

Some additional effects, also influencing precipitation, are contained in the proportionality factor $P_{0}$ :

$$
P_{0}=P_{1}\left(1+P_{2}\left|\frac{\partial h_{\mathrm{s}}}{\partial x}\right|\right) 2^{-\max \left(0 ; h_{\mathrm{S}}-\left(2+h_{\mathrm{s} 1}\right)\right)} \tau\left(T_{0}\right) .
$$

By Equation (6), precipitation increases with the surface slope $\left|\partial h_{\mathrm{S}} / \partial x\right|$ of the ice sheet, thus simulating orographic rain. $P_{1}$ is the average precipitation in mid-latitudes and $P_{2}$ was chosen such that the model precipitation fits the observations in mountain areas of North America. The form (6) includes the "elevation-desert effect" (Budd and Smith, 1979) with $h_{\mathrm{s}}$ the sea-level height, and a factor $\tau\left(T_{0}\right)$, which crudely models the (linear) reduction in precipitation with decreasing global temperature $T_{0}$.

The snowfall $s$ in the model depends on precipitation and surface temperature $\left(s=P\right.$ for $T_{\mathrm{S}}<0$, and $s=0$ otherwise). Following Pollard (1980), snow melt is parameterized linearly in terms of surface temperature and solar insolation. The annual balance $b$ of snowfall and snow melt follows by integrating over the year.

\section{RESULTS AND CONCLUSIONS}

The aim of the first numerical experiment was to build up a typical ice-age ice sheet within a realistic time. Using
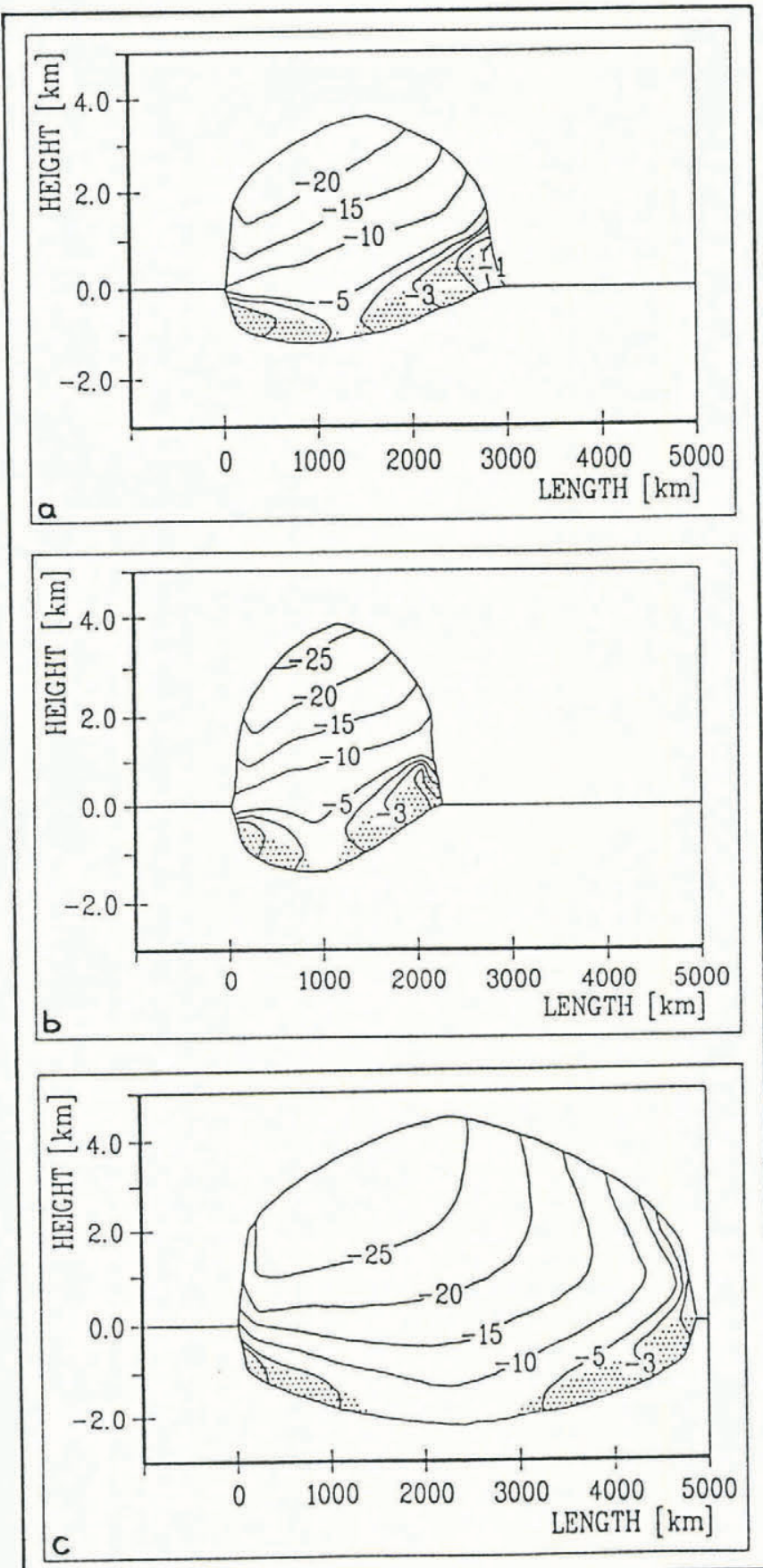

Fig. 2. Ice-sheet shape and isolines of temperature $\left({ }^{\circ} \mathrm{C}\right)$. Dotted areas indicate temperate ice (a) after 35000 model years integration (with temperature-flow coupling), (b) after 35000 model years integration (without temperature-flow coupling), (c) after 200000 model years integration (with temperature-flow coupling). 
the parameterization (6) for precipitation fitted to present-day observations, the Laurentide ice sheet reaches an extent of $3300 \mathrm{~km}$ and a maximum height of $3770 \mathrm{~m}$ within a build-up time of 40000 years.

Figure 2a shows the temperature field within the model ice sheet after 35000 model years. The temperature increases from the ice surface towards the base. Near the base, however, a temperature inversion is visible. This inversion is due to temperate regions (dotted areas), where the ice is at the pressure melting point everywhere. These temperate regions started to develop after 15000 model years near the southern edge of the ice sheet. The existence of temperate regions within an ice sheet requires an internal energy source, which is the heat released by deformation. The occurrence of temperate regions in ice-age ice sheets has not yet been reported by other modelers. Since we did not expect to have such temperate regions occurring in our model, we were also not prepared to treat the ice deformation in these regions properly. In the model, the temperature was simply not allowed to rise above the pressure melting point and the deformation was calculated as if it were ice at the pressure melting point, without considering the complexities introduced by melting.

Figure $2 \mathrm{~b}$ shows another model run, also over 35000 model years, but without temperature-flow coupling. The flow was calculated assuming a mean ice temperature of $-10^{\circ} \mathrm{C}$. This build-up experiment produces a higher ice sheet with a shorter southern extent compared to the build-up experiment with temperature-flow coupling. The thickness-to-length ratio is now unrealistically high (increased by a factor of about 1.5). This difference in ice-sheet shape reflects the strong temperature dependence of ice flow. The flow increases by a factor 10 from $-10^{\circ}$ to $0^{\circ} \mathrm{C}$. Since the ice-sheet shape influences its own mass balance, we conclude that ice temperature is an indispensable model variable which has to be included in a realistic ice-sheet model.

An almost-stationary state of the ice sheet is achieved after about 200000 model years integration (see Fig. 2c). For a stationary state, the amount of accumulated snow over the year has to be equal to the amount of ice melting away. In our model, the ice sheet needs more than 100000 years build-up time to arrive at a nearly stationary shape. Its length is then approximately $5000 \mathrm{~km}$. The ice sheet needs another 100000 years to achieve a stationary temperature distribution. We infer from this result that the Laurentide ice sheet was probably never in a stationary state. The temperature distribution of this stationary state differs from the temperature distribution during the initial phase of ice-sheet build-up. In the build-up phase, heat diffusion produces an almost constant vertical temperature gradient. In the stationary state advection of cold ice has flattened the gradient in the upper half of the ice sheet, with a steepening below. Temperate regions are still present, but their vertical extent is now reduced.

In a final experiment, the almost-stationary state of the ice sheet was forced stochastically. Our intention was to study the effect of short time-scale weather fluctuations on the evolution of the ice sheet. Weather fluctuations occur on time scales of hours to days, which is small compared to the response time of ice sheets (on the order of 10000 years and longer). The weather fluctuations will therefore be treated as a white-noise process, formally introduced in the model by splitting the proportionality factor $P_{0}$ in Equation (5) into a mean and a fluctuating part, with a variance equal to the square of the mean. For interpretation of the resulting model time series (and spectrum) we used standard methods of spectral analysis. The resulting time constant is near 18000 years. The induced stochastic changes of the ice volume had an amplitude of about $10 \%$ of the total volume. This leaves $90 \%$ of the change between minimum and maximum ice volume to be explained by deterministic processes. In the case of a stronger positive feedback between the ice sheet and the atmosphere than incorporated in our model, this amplitude may be much larger (Oerlemans, 1979). The stochastic component, however, cannot be too large. Otherwise, it would be hard to explain the observed high coherence between the changes of solar insolation and the ice-volume record (Imbrie and others, 1984).

\section{REFERENCES}

Birchfield, G.E., J. Weertman, and A.T. Lunde. 1981. A paleoclimate model of Northern Hemisphere ice sheets. Quat. Res., 15(2), 126-142.

Bowman, K.P. 1982. Sensitivity of an annual mean diffusive energy balance model with an ice sheet. J. Geophys. Res., 87(C12), 9667-9674.

Budd, W.F. and I.N. Smith. 1981. The growth and retreat of ice sheets in response to orbital radiation changes. International Association of Hydrological Sciences Publication 131 (Symposium at Canberra $1979-$ Sea Level, Ice and Climatic Change), 369-409.

Hays, J.D., J. Imbrie, and N.J. Shackleton. 1976. Variations in the Earth's orbit: pacemaker of the ice ages. Science, 194(4270), 1121-1132.

Herterich, K. 1988. A three-dimensional model of the Antarctic ice sheet. Ann. Glaciol., 11, 32-35.

Holton, J.R. 1979. An introduction to dynamic meteorology. Second edition. New York, Academic Press. (International Geophysics Series 23.)

Hutter, K. 1983. Theoretical glaciology; material science of ice and the mechanics of glaciers and ice sheets. Dordrecht, etc., D. Reidel Publishing Company/Tokyo, Terra Scientific Publishing Company.

Imbrie, J., and 8 others. 1984. The orbital theory of Pleistocene climate: support from a revised chronology of the marine $\delta^{18} \mathrm{O}$ record. In Berger, A., J. Imbrie, J. Hays, G. Kukla, and B. Saltzman, eds. Milankovitch and climate; understanding the response to astronomical forcing. Dordrecht, etc., D. Reidel Publishing Company, 269-305. (NATO ASI Ser. C 126.)

Morland, L.W. 1984. Thermomechanical balances of ice sheet flows. Geophys. Astrophys. Fluid Dyn., 29 237-266.

North, G.R. 1975. Theory of energy-balance climate models. J. Atmos. Sci., 32, 2033-2043.

Oerlemans, J. 1979. A model of a stochastically driven ice sheet with planetary wave feedback. Tellus, 31(6), 469-477.

Oerlemans, J. and C.J. Van der Veen. 1984. Ice sheets and climate. Dordrecht, etc., D. Reidel Publishing Company.

Paterson, W.S.B. 1981. The physics of glaciers. Second edition. Oxford, etc., Pergamon Press.

Pollard, D. 1980. A simple parameterization for ice sheet ablation rate. Tellus, $32,384-388$.

Pollard, D. 1983. A coupled climate-ice sheet model applied to the Quaternary ice ages. J. Geophys. Res., 88(C12), 7705-7718.

Weertman, J. 1976. Milankovitch solar radiation variations and ice-age ice-sheet sizes. Nature, 261(5555), 17-20. 